\title{
Depression and smoking in pregnancy in Scotland
}

\author{
Colin W Pritchard
}

\begin{abstract}
Objective - The aim was to examine the association between depressive symptoms and smoking in pregnancy and to investigate the part played by social and psychosocial factors.

Setting - A single Glasgow hospital.

Design - Prospective survey by postal questionnaires at 20 and 30 weeks' gestation.

Participants - A total of 395 women (69\% of the 572 eligible) parity 1 who booked for delivery between November 1988 and February 1990 took part.

Measurements - Depressive symptoms were measured using the Hospital Anxiety and Depression Scale. Smoking was self reported. The Life Events Inventory and measures of role specific strain and stress in domestic roles were used to assess psychosocial well being.

Main results - Smokers were more likely than non-smokers to experience depressive symptoms at 20 and 30 weeks' gestation and on both occasions. The excess risk remained substantial and significant after adjustment for social and psychosocial factors.

Conclusions - Smoking is a significant risk factor for depression in pregnancy. The association of smoking with depression and psychosocial difficulty represents a major problem for interventions intended to reduce smoking in pregnancy.
\end{abstract}

\section{( $\mathcal{F}$ Epidemiol Community Health 1994;48:377-382)}

The adverse effects of smoking on the course and outcome of pregnancy have been extensively documented. ${ }^{1}$ Because of the known dangers and because they are in contact with health care professionals over the antenatal period, pregnant women have been particular targets for a wide range of antismoking initiatives. ${ }^{23}$ One explanation suggested for the relatively poor success of these efforts has been that smokers commonly report that smoking alleviates dysphoric moods ${ }^{4-6}$ and a possible mechanism, through an effect on centrally acting neuroregulators, has been suggested. ${ }^{7}$

Associations between smoking and negative emotional states, however, have also been noted in several studies. For example, WaalManning and de $\mathrm{Hammel}^{8}$ reported that smokers tended to have higher scores on symptomatic measures of anxiety and depression than non-smokers and Anda et al reported that the proportion of smokers increased across quintiles of the Center for Epidemiologic Studies Depression Scale. Smoking has been associated with severe de- pression in clinic $^{10}$ and community ${ }^{11}$ based studies, and in a study of the psychological correlates of coronary artery disease. ${ }^{12} \mathrm{~A}$ possible explanation for the contradiction between the reported emotional "benefits" of smoking and the observation of relatively high rates of depression among smokers is that people who are depressed find it more difficult to stop smoking ${ }^{913}$ or are more likely to relapse. ${ }^{14}$

The association between smoking and depression may, however, be confounded by factors that are independently associated with both smoking and depression. In Britain, as in other developed countries, smoking has increasingly become associated with poor socioeconomic circumstances. ${ }^{15}$ Associations between lower social class and a higher risk of depression have been noted for some time. ${ }^{1617}$ The situation is further complicated by the possibility that both associations may be mediated by psychosocial factors.

This paper describes the associations of smoking, depression, and potential socioeconomic and psychosocial confounding factors that were found in a prospective, hospital based study of pregnant women.

\section{Sample and data}

The data presented in this paper come from a study of mothers who were expecting their second child and who booked for delivery in a single Glasgow hospital between November 1988 and February 1990. The data described come from two postal questionnaires which were completed at 20 and 30 weeks' gestation. There was a total of 572 women of parity 1 who booked for delivery before 20 weeks' gestation and whose pregnancy continued beyond 30 weeks. Of these, 398 returned both questionnaires, but in three cases the measure of depression was not fully completed. Thus, this paper reports data for 395 women, $69 \%$ of those eligible for inclusion in the study.

The measurement of depression reported is the depression subscale of the Hospital Anxiety and Depression (HAD) scale ${ }^{18}$ in which scores range between 0 and 21 . Scale scores between 0 and 7 are classified as "not depressed", scores between 8 and 10 are classified as "possible case", and those between 11 and 21 are classified as "case depressed". Because the HAD scale was completed at 20 and 30 weeks, it is possible to identify a group of women who experienced significant depressive symptoms on both occasions. This group comprises those who were "case depressed" at both 20 and 30 weeks and those who were "case depressed" on one occasion and "possible case" on the other. Although this group is referred to as experiencing "prolonged depression" it clearly comprises some women who 
experienced episodes of depression on both occasions as well as those who were depressed over the whole period. Nevertheless, the classification will tend to identify women for whom depression during pregnancy was a particular problem because episodes of depression were either relatively frequent or of relatively long duration.

Data on self reported smoking status were collected at 20 and 30 weeks. One woman who reported not smoking at 20 weeks, but reported smoking at 30 weeks has been included among the smokers. No woman who reported smoking at 20 weeks reported not smoking at 30 weeks.

The husband's or partner's social class was coded using the Registrar General's social class scheme. ${ }^{19}$ Previous occupations of those husbands or partners who were unemployed have not been coded, nor have the occupations of single women who were not cohabiting: these groups are reported separately. In one case occupational and marital status information was not codable.

"Tenure" refers to housing tenure and is reported as rented or owner occupied.

Income data comprise self reported total weekly household income and has been coded as incomes less than $f 100 \mathrm{pw}$ and incomes of $£ 100$ pw and over. Respondents could choose not to answer questions about their income and $42(10 \cdot 6 \%)$ declined to answer.

The Life Events Inventory was used to provide data on potentially stressful life events over the last year at 20 weeks' gestation and over the interval between the two questionnaires at 30 weeks. The events recorded at 30 weeks were scrutinised to avoid the possibility of "double counting". Scores at 30 weeks" gestation comprise the events recorded in both questionnaires. The Life Events Inventory was scored according to the weightings recommended by Cochrane and Robertson. ${ }^{20}$ The event of "pregnancy" was not included in the schedule and has not been scored.

The paper also reports measures of role specific strain and stress in the household and marital roles. The form of psychosocial difficulty referred to by the concepts of role specific strain and stress was originally described by Pearlin and Schooler. ${ }^{2122}$ Briefly, from this perspective, participation in ordinary daily social roles is viewed as entailing a set of normative expectations and recurring situations which are specific to particular roles. The frustration of expectations or the persistent demands or difficulties of social circumstances related to the role are seen as potential threats to psychological well being and are referred to as "role specific strains". These strains may contribute to the experience of emotional upset or distress associated with participation in a particular social role and these negative feelings are referred to as "role specific stress". Role specific stress is thought of as distinct from the more global and diffuse states of anxiety or depression in that it is specific to participation in a specific social role. The extent to which problems, represented by strains, give rise to feelings of unhappiness, represented by stress, are seen as being mediated by the individual's ability to "cope" with the challenges inherent in the role. Altogether, the formulation emphasises the importance of social roles in creating and maintaining the experience of psychosocial malaise over long periods.

The questionnaire items used derive from Pearlin and Schooler ${ }^{21}$ and from Kandel, Davies, and Raveis, ${ }^{23}$ with minor modifications in wording as a result of pilot studies. Questionnaire items for strains consisted of four point scales indicating the respondents' agreement or disagreement with first person statements identifying potential role strains. Positive responses, indicating the perception of strain, were coded 1 or 2 depending on the strength of agreement or disagreement with the statement: the negative responses were coded 0 . For both household and marital roles, three subscales, referring to different aspects of strain were included in the questionnaires ${ }^{2123}$ and addressed in three or four questionnaire items. The score for each of the subscales was the sum of the item scores classified as "low strain" if the score was 0 or 1 , and "high strain" if the score exceeded the number of items in the subscale (indicating strong agreement or disagreement with at least one item. The residual group were classified as "intermediate strain". For the summary measure reported in this paper, "low strain" consists of those who were classified as "low strain" on each of the subscales within the role and "high strain" as those who were classified as "high strain" on any one of the subscales of the role. "Intermediate strain again identifies those who were not classified as either "low" or "high" strain on the summary measure.

For each role, role specific stress was measured by a check list of seven adjectives describing feelings about participation in the role. Respondents were asked to indicate the frequency with which they experienced the feelings in four categories ranging from "very often" to "never". A score of 0 was given to responses indicating infrequent negative feelings or frequent positive feelings. Scores indicating frequent negative feelings or infrequent positive feelings were scored 1 or 2 depending on the frequency reported. Total scores of 0 or 1 were coded as low stress, those between 2 and 4 were classified as "intermediate stress", and the "high stress" group comprises those with scores of 5 or more.

\section{Results}

The figure shows the distributions of $\mathrm{HAD}$ scale depression classes for the sample at 20 and 30 weeks' gestation. There was a strong association between scores on the two occasions $\left(\chi^{2}=128.60,4 \mathrm{df}, \mathrm{p}<0.001\right)$, but rates of "case" and "possible case" depression both increased. While the proportion of "case depressed" at 20 weeks $(6.0 \%)$ was lower than the $13.0 \%$ found by Zigmond and Snaith ${ }^{18}$ in their general sample of outpatients, the rate at 30 weeks $(12 \cdot 1 \%)$ was similar. The rate of "prolonged depression" (defined above) for the sample was $10 \cdot 4 \%$. 
20 weeks' gestation

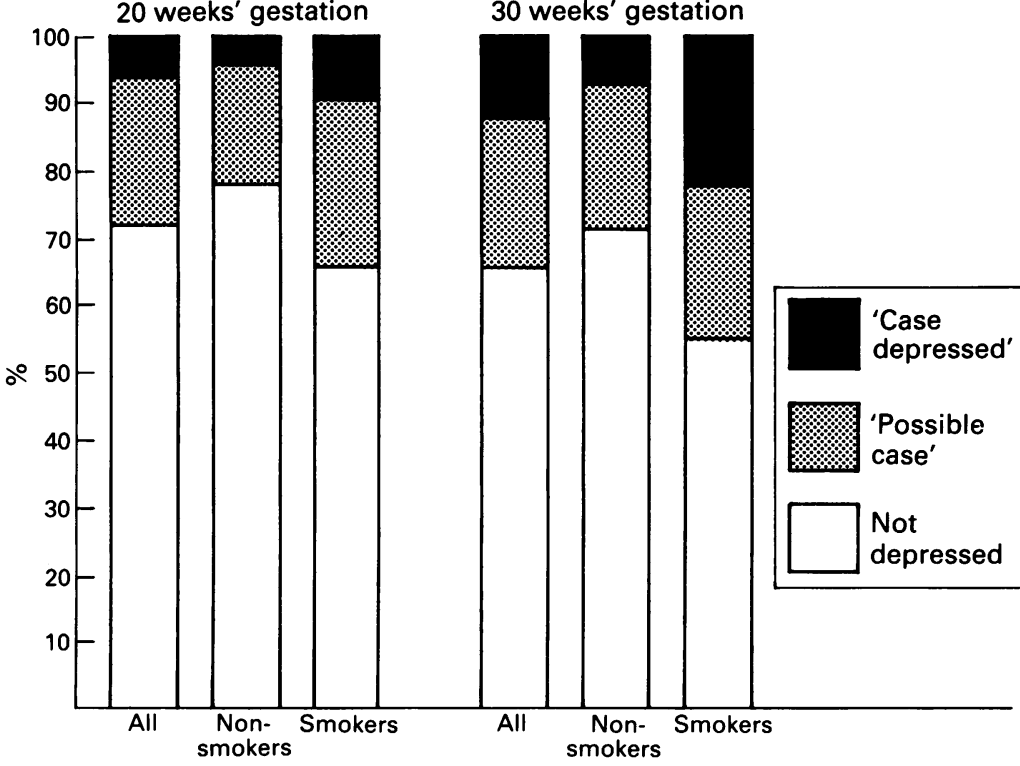

Distributions of Hospital Anxiety Scale depression classes by smoking at 20 and 30 weeks' gestation.

\begin{tabular}{lllllll}
\hline Data table & 20 weeks & \multicolumn{5}{c}{30 weeks } \\
\hline & $\begin{array}{l}\text { Case } \\
\text { depressed } \\
(\%)\end{array}$ & $\begin{array}{l}\text { Possible } \\
\text { depressed } \\
(\%)\end{array}$ & $\begin{array}{l}\text { Not } \\
\text { depressed } \\
(\%)\end{array}$ & $\begin{array}{l}\text { Case } \\
\text { depressed } \\
(\%)\end{array}$ & $\begin{array}{l}\text { Possible } \\
\text { depressed } \\
(\%)\end{array}$ & $\begin{array}{l}\text { Not } \\
\text { depressed } \\
(\%)\end{array}$ \\
\hline All & $6 \cdot 1$ & $12 \cdot 4$ & $81 \cdot 5$ & $12 \cdot 2$ & $22 \cdot 0$ & $65 \cdot 8$ \\
Non-smokers & $4 \cdot 7$ & $6 \cdot 9$ & 88.4 & $7 \cdot 6$ & 20.7 & $71 \cdot 7$ \\
Smokers & $9 \cdot 2$ & $25 \cdot 2$ & 65.5 & $22 \cdot 7$ & $25 \cdot 2$ & $52 \cdot 1$ \\
\hline
\end{tabular}

There were $119(30 \cdot 1 \%)$ smokers in the sample and the figure also shows the distributions of HAD depression subscale classes for smokers and non-smokers at 20 and 30 weeks' gestation. Smoking was significantly associated with depressive symptoms on both occasions (20 week $\chi^{2}=30.65,2 \mathrm{df}, \mathrm{p}<0.001: 30$ week $\left.\chi^{2}=21.22,2 \mathrm{df}, \mathrm{p}<0.001\right)$. In particular, smokers were significantly more likely to be "case depressed" at 30 weeks: at 30 weeks the rates of "case depression" were $22.5 \%$ for smokers and $7.6 \%$ for non-smokers (OR $=3.54,95 \%$ confidence interval (95\% $\mathrm{CI})=1 \cdot 92,6 \cdot 61)$. Altogether $22 \cdot 7 \%$ of smokers and $5 \cdot 1 \%$ of non-smokers experienced "prolonged depression" ( $O R=5 \cdot 49,95 \%$ CI $2 \cdot 76$, 10.93).

Within the general tendency for depressive symptoms to increase, the figure seems to suggest that smokers experienced a sharper increase than non-smokers. Analysis of the unclassified scale scores, however, suggests an alternative explanation. Calculating the difference between the scores at 30 and 20 weeks gives a continuous distribution which indicates the extent of changes over the 10 week period. Similar proportions of smokers and non-smokers, $17.6 \%$ and $17.0 \%$ respectively, show a reduction in the score. A slightly higher proportion of smokers $(62.2 \%)$ than nonsmokers $(59.1 \%)$ experienced an increase in the level of depressive symptoms, but the difference is not statistically significant. Comparing the cumulative distributions of the changes between 20 and 30 weeks for smokers and non-smokers using the KolmogorovSmirnov two sample test indicates that they are not significantly different $(\mathrm{K}-\mathrm{S} \max =0.34$; $\mathrm{K}-\mathrm{S} \mathrm{Z}=0.39$ ). What this suggests is that both smokers and non-smokers shared in a common process of change in depressive symptoms between 20 and 30 weeks' gestation in which the predominant tendency is for the level of symptoms to increase. The greater increase in the proportion of smokers who experience severe ("case") depression would then be explained by the higher levels of symptoms in smokers at 20 weeks.

The effects of smoking may mimic the somatic symptoms of depression without indicating the presence of a mood disorder. Although the questionnaire items in the HAD scale were selected to avoid somatic confounding, ${ }^{18}$ particular items might account for the smokers' higher scores on the scale. Because smokers tend to have higher levels of depressive symptoms, it would be anticipated that they would tend to have higher scores on the items comprising the scale. With one exception, this is consistently the case for each of the items at 20 and at 30 weeks. The exception is the item "I feel as if I am slowed down" where the distributions of responses for smokers and nonsmokers were similar at both 20 and 30 weeks $\left(\chi^{2} 20\right.$ weeks $=6.97,3 \mathrm{df}: \chi^{2} 30$ weeks $=2 \cdot 75$, $3 \mathrm{df})$. The lack of difference for this item, which was the commonest "symptom" on both occasions, may reflect the physical effects of pregnancy across all of the women in the sample. If the differences between smokers and non-smokers were accounted for by particular items from the scale, smokers who experienced significant depression ("possible case" and "case depressed") would be expected to have a different pattern of symptoms from that of "depressed" non-smokers. At 20 weeks there were no significant differences between "depressed" smokers and non-smokers for any of the items. At 30 weeks, smokers differed from non-smokers only in response to the item "I can laugh and see the funny side of things" $\left(\chi^{2}=6.53,2 \mathrm{df}^{*}\right.$; $\mathrm{p}<0.05)$, where a smaller proportion of smokers $(8.6 \%)$ than non-smokers $(22.8 \%)$ answered "As much as I always could". Altogether, smokers were more likely than nonsmokers to experience the whole range of the symptoms of depression included in the HAD scale and depressed smokers had a similar pattern of symptoms to that experienced by non-smokers. The differences in rates of depression between smokers and non-smokers cannot be accounted for in terms of particular scale items.

Rates of depressive symptoms did not vary significantly with social class, low income, housing tenure, or marital status at either 20 or 30 weeks. The rate of "prolonged depression", however, was significantly associated with both social class $\left(\chi^{2}=6.83,2 \mathrm{df}, \mathrm{p}<0.05\right)$ and marital status $\left(\chi^{2}=9.83,2 \mathrm{df}, \mathrm{p}<0.01\right)$. Women with husbands or partners in manual employment and women who were unmarried but cohabiting had higher rates of "prolonged depression". 
Smoking, in this sample, was associated with socioeconomic factors: those with husbands or partners in manual employment, those with low household incomes, those living in rented accommodation, and those who were unmarried were more likely to smoke. It is thus possible that, at least in part, the higher rates of "prolonged depression" in smokers could be explained in terms of social class or marital status. Smokers, however, showed higher rates of depressive symptoms contingent on their social class and marital status. LOGIT models incorporating only the main effects of smoking fit the data well: neither social class $\left(\chi^{2}=5.94,6 \mathrm{df}, \mathrm{p}=0.43\right)$ nor marital status $\left(\chi^{2}=4 \cdot 74,4 \mathrm{df}, \mathrm{p}=0.32\right)$ were significantly associated with depression once smoking has been taken into account. However, the persistence of social class and marital status variations within smoking categories does suggest that the less parsimonious main effects models - in which smoking and social class or marital status have independent effects on the likelihood of depression - are reasonable accounts of the data.

Smokers had significantly higher scores than non-smokers on the Life Events Inventory and those who were depressed had higher scores than those who were not depressed, although, because there were relatively few women "case depressed" at 20 weeks, the possibility that the higher average score might have occurred by chance cannot be ruled out. After adjustment for the association between scores on the Life Events Inventory, the odds ratios for "case depression" associated with smoking were $1.82(95 \%$ CI $0.71,4.64)$ at 20 weeks and 3.22 $(95 \%$ CI $1.64,6.36)$ at 30 weeks: the adjusted odds ratio for "prolonged depression" was $4 \cdot 83(95 \% \mathrm{CI}=2 \cdot 39,9 \cdot 77)$. Although the confidence intervals for the odds ratio at 20 weeks overlap unity, the figures do not suggest that the association between smoking and depression is to be explained by differences in the scores on the Life Events Inventory.

HAD scale depression classes and the measure indicating prolonged depressive symptoms were significantly associated with the frequency of negative feelings about participation in both the household and marital roles (role specific stresses) and with the summary measures of role specific strain at 20 and 30 weeks. Women with low levels of role specific difficulties at 20 weeks were less likely to experience an increase in the level of depres-

Table 1 Odds ratios of prolonged depression in smokers adjusted for role specific psychosocial factors (values, odds ratios (OR) and $95 \%$ confidence intervals)

\begin{tabular}{|c|c|c|c|}
\hline Adjusted for: & & $\begin{array}{l}\text { Household } \\
\text { role }\end{array}$ & $\begin{array}{l}\text { Marital } \\
\text { role }\end{array}$ \\
\hline $\begin{array}{l}\text { Measures taken at } \\
20 \text { weeks' gestation: }\end{array}$ & $\begin{array}{l}\text { Strain } \\
\text { Stress } \\
\text { Strain } \\
+ \text { stress }\end{array}$ & $\begin{array}{l}5.00(2.47,10 \cdot 13) \\
4.50(2.20,9 \cdot 17) \\
4.06(1.22,9.41)\end{array}$ & $\begin{array}{l}5.15(2.52,10.54) \\
5.13(2.52,10.44) \\
4.95(2.41,10.20)\end{array}$ \\
\hline $\begin{array}{l}\text { Measures taken at } \\
30 \text { weeks' gestation: }\end{array}$ & $\begin{array}{l}\text { Strain } \\
\text { Stress } \\
\text { Strain } \\
\text { + stress }\end{array}$ & $\begin{array}{l}5.45(2.68,11 \cdot 09) \\
4.81(2.21,9 \cdot 17) \\
4 \cdot 70(2.28,9 \cdot 71)\end{array}$ & $\begin{array}{l}4.94(2.42,10 \cdot 10) \\
4.80(2 \cdot 36,9 \cdot 79) \\
4.50(2 \cdot 18,9 \cdot 29)\end{array}$ \\
\hline
\end{tabular}

sive symptoms at 30 weeks: this was the case in both roles and for role specific strains (household strain $\mathrm{OR}=0.52,95 \%$ CI $0.31,0.89$ : marital strain $\mathrm{OR}=0 \cdot 22,95 \% \mathrm{CI}=0 \cdot 15,0 \cdot 51$ ) and role specific stresses (household stress $\mathrm{OR}=0.56,95 \%$ CI $0.27,0.77$ : marital stress $\mathrm{OR}=0.49,95 \%$ CI $0.30,0 \cdot 79$ ).

Smoking was also significantly associated with the stresses of household and marital roles at 20 and 30 weeks and - less strongly with the strains of both roles at 20 weeks and the strains in the marital role at 30 weeks. If psychosocial difficulties were implicated in causing or maintaining depression, the patterns of association with smoking and depression suggest a model in which smokers experience higher levels of role specific difficulties which would, in turn, be associated with increased frequencies of negative feeling about role participation. This form of psychosocial stress could then contribute to the higher levels of depressive symptoms amongst smokers.

Such a model does not, however, fit the data. Rates of depressive symptoms at 20 and 30 weeks and of the measure of "prolonged depression" show strong and consistent gradients with strains and stresses in each of the roles, both overall and within smoking categories. However, with the exception of "prolonged depression" in those with low stress in the household role, smokers are consistently more likely to be depressed than non-smokers within strain and stress categories. LOGIT analysis shows that the odds of depression continued to be significantly higher for smokers after adjustment for role specific strains and stresses. Table 1 illustrates the analysis for "prolonged depression". Although the odds ratios are reduced by adjustment for role specific strains and stresses, the odds of experiencing "prolonged depression" remained more than four times greater for smokers than non-smokers after adjustment.

Although the study was not large enough to conduct a useful analysis including all the psychosocial factors together, it is possible to identify a group of $47(11.9 \%)$ women who experienced strains and stresses in both roles at both 20 and 30 weeks and who were in the top quartile of the scores for the Life Events Inventory. Of these 47,25 were smokers $(\mathrm{OR}=3 \cdot 07,95 \%$ CI $1 \cdot 65,5 \cdot 71)$. Table 2 shows the rates of "prolonged depression" for women in this group and in the rest of the sample in relation to smoking. "Prolonged depression" is significantly associated with

Table 2 Rates of prolonged depression by "high psychosocial risk" and smoking (values, percentage depressed and number)

\begin{tabular}{llll}
\hline & $\begin{array}{l}\text { Non- } \\
\text { smokers }\end{array}$ & Smokers & All \\
\hline Not "high & $4 \cdot 7$ & $18 \cdot 1$ & $8 \cdot 33$ \\
risk" & $(12 / 254)$ & $(17 / 94)$ & $(29 / 348)$ \\
"High risk" & $9 \cdot 1$ & $40 \cdot 0$ & $25 \cdot 5$ \\
& $(2 / 22)$ & $(10 / 25)$ & $(12 / 47)$ \\
All & $5 \cdot 1$ & $22 \cdot 7$ & $10 \cdot 4$ \\
& $(14 / 276)$ & $(27 / 119)$ & $(41 / 395)$ \\
\hline
\end{tabular}


membership of this high risk group (adjusted $\mathrm{OR}=2 \cdot 67,95 \% \mathrm{CI} 1 \cdot 21,5.98)$ and with smoking (adjusted OR $=4 \cdot 81,95 \%$ CI $2 \cdot 39,9 \cdot 71$ ). The interaction between group membership and smoking was not significant $\left(\chi^{2}=0 \cdot 19\right.$, $1 \mathrm{df})$. Even in a group of women at high psychosocial risk, smoking remains a significant independent risk factor for depression.

\section{Discussion}

This paper confirms that the association between smoking and symptoms of depression, which has been reported in the general population $^{11}$ and in particular patient groups $^{1012}$ is also present in a sample of pregnant women. In this sample smoking was a risk factor for depression at 20 and at 30 weeks' gestation and smokers were more likely to experience depression on both occasions.

Four possible influences on depressive symptoms in pregnancy have been described in relation to the observed association between smoking and depression. Firstly, it was shown that smokers were more likely to experience all but one of the depressive symptoms included in the HAD scale and that the pattern of symptoms in women classified as depressed did not differ significantly in relation to smoking. These findings are not consistent with the hypothesis that raised rates of depression in smokers are due to some form of somatic confounding.

Secondly, the relationship between depressive symptoms and gestation was considered. While some researchers have found that pregnant women experience a relatively stable mood across pregnancy and that pregnancy is a time of particularly good psychological adjustment, ${ }^{24-26}$ others have reported that a substantial proportion of women experience emotional distress and lability which tends to increase with gestation. ${ }^{27-29}$ Ballinger $^{30}$ found an increase in depressive symptomology between the second and third trimesters in the context of relatively stable measures of other aspects of emotional well being.

The women in this sample had young children at home, and thus comprised a group at particular risk of depression. ${ }^{31}$ However, this study found relatively low rates of depression at 20 weeks' gestation. The prevalence of depressive symptoms increased between 20 and 30 weeks, but overall rates of depression at 30 weeks were not higher than those found in other patient groups. ${ }^{18}$ Although rates of "case depression" showed a greater increase than those for non-smokers, this finding was consistent with a general increase in symptoms of depression irrespective of smoking.

Thirdly, the possibility that the association of smoking with depression was confounded by socioeconomic factors was examined. The relationship of smoking and depression was independent of socioeconomic factors: smokers were consistently more likely to be depressed than non-smokers within categories of the socioeconomic indicators.

Finally, two forms of psychosocial difficulty were investigated. Depression and smoking were each associated with scores on the Life Events Inventory and with measures of role specific stress. Although different prevalences of adverse psychosocial circumstances accounted for some of the excess risk of depression in smokers, the association of depression with smoking appears largely independent of these other risk factors.

The strong consistent association of smoking with depression raises difficult questions of causality. In particular, the question of whether smoking precedes or follows depressed mood remains unresolved. ${ }^{5}$ Previous reports have shown that depression plays a part in the initiation ${ }^{32}$ and persistence ${ }^{9}$ of the smoking habit. It has been suggested that people with depressive disorders may be particularly susceptible to nicotine addiction. ${ }^{33}$ Among the women included in this study, however, the current experience of psychosocial difficulty in daily domestic roles was associated with higher rates of smoking. While the perception and emotional response to these difficulties may, in part, be explained by a more generalised mood disorder, adverse psychosocial circumstances were associated with smoking irrespective of depression. Those with relatively high scores on the Life Events Inventory were also more likely to smoke than those with low scores. Taken together these findings suggest that, even if a long standing tendency to depression is a major factor in smoking, immediate psychosocial circumstances play an important part.

Whilst the set of associations between smoking, depression, and psychosocial factors raise intractable issues of causal priority, they do present considerable difficulties for those who seek to encourage smoking cessation in pregnant women. Depressed smokers are less likely to succeed in giving up smoking than nondepressed smokers ${ }^{1134}$ and are more likely to relapse. ${ }^{14}$ The belief that smoking is an effective method of coping with psychosocial stress is commonly reported ${ }^{35}$ and provides a powerful motivation for continuing to smoke amongst those who experience psychosocial difficulties. Although the psychosocial factors considered in this study are by no means exhaustive, $60.2 \%$ of smokers experienced some form of psychosocial difficulty: $22 \cdot 7 \%$ of smokers experienced "prolonged depression". In this sample, not one woman who was smoking at 20 weeks had stopped smoking by 30 weeks.

Interventions designed to reduce smoking in pregnancy with feedback on the adverse effects of continued tobacco use and the deployment of biochemical markers to monitor smoking behaviour may be effective for well motivated women who feel optimistic about their lives and pregnancies ${ }^{3}$ but may also provide some smokers with further threatening evidence of their perceived inadequacy and lack of worth.

Antenatal services tend to be preoccupied with the physical care and safety of the mother and fetus. Nevertheless, emotional well being is an important aspect of women's health in pregnancy. Although most women in this study experienced relatively low levels of 
depressive symptoms, for a significant proportion, pregnancy was a time of psychological disturbance and psychosocial difficulty. The observation that most of these smoked during their pregnancies adds to arguments for a more careful consideration of psychological factors in the design both of antenatal care in general and of specific health care initiatives in pregnancy.

Thanks are due to the women whose participation made this study possible, to Dr P Teo who was a part of the study team,
and to the staff of the Southern General Hospital, Glasgow, for and to the staff of the Souther

The Public Health Research Unit is supported by the Scot-
The Puboration and help. The Public Health Research Unit is supported by the Scot-
ish Home and Health Department and by the Greater Glasgow tish Home and Health Department and by the Greater Glasgow
Health Board. Opinions expressed in this paper are not necesHealth Board. Opinions expressed in this paper are not neces-
sarily those of the Scottish Home and Health Department.

1 Editorial. Maternal smoking in pregnancy. Paediatr Perina Epidemiol 1988;2(1):2-3.

2 Lumley J. Stopping smoking. Br $\mathcal{f}$ Obstet Gynaecol 1987;94:289-92.

3 Lumley J. Stop smoking - again. Br $\mathcal{f}$ Obstet Gynaecol 1991;98:847-9.

4 Ashton H, Stepney R. Smoking as a psychological tool. In Smoking psychology and pharmacology. London: Tavistock, 1982:91-119.

5 Carmody TP. Affect regulation, nicotine addiction and smoking cessation. f Psychoactive Drugs 1989;21:331-42.

6 Hughes JR. Clonidine, depression and smoking cessation. fAMA 1988;259:2901-2.

7 Pomerleau OF, Pomerleau CS. Neuroregulators and the reinforcement of smoking: towards a biobehavioral explareinforcement of smoking: towards a biobehavior

8 Waal-Manning HJ, de Hammel FA. Smoking habit and psychometric scores: a community study. NZ Med $\mathcal{f}$ 1978;88:188-91.

9 Anada RF, Williamson DF, Escobedo LG, Mast E, Giovino GA, Remington PL. Depression and the dynamics of smoking. $\mathcal{F} A M A$ 1990;264(12):1541-5.

10 Hughes JR, Hatsukami DK, Mitchell JE, Dahlgren LA Prevalence of smoking among psychiatric outpatients. $A m$ I Psychiatry 1986;143:993-7.

11 Glassman AH, Helzer JE, Covey LS, Cottler LB, Stetner F, Tipp JE, Johnson J. Smoking, smoking cessation and major depression. $7 A M A$ 1990;264(12):1547-9.

12 Carney RM, Rich MW, Tevelde A, et al. Major depressive disorder in coronary artery disease. Am $\mathfrak{f}$ Cardiol disorder in cor

13 Covey LS, Glassman AH, Stetner F. Depression and depres- sive symptoms in smoking cessation. Comp Psychiatry 1990;31:350-4.

14 Shiffman $S$. Relapse following smoking cessation: a situational analysis. $\mathcal{f}$ Clin Psychol 1982;50:71-86.

15 Office of Population Censuses and Surveys. Cigarette smoking: 1972-1982. OPCS Monitor GHS 83.3, London: HMSO, 1983 .

16 Dohrenwend BP, Dohrenwend BS. Social status and psychological disorder: a causal inquiry. New York: John Wiley, 1969.

17 Warheit G, Holzer C III, Schwab J. An analysis of social class and racial differences in depressive symptom-aetiology: a community study. F Health Soc Behav 19??;4:9219.

18 Zigmond AS, Snaith RP. The Hospital Anxiety and Depression Scale. Acta Psychiatr Scand 1983;67:361-70.

19 Office of Population Censuses and Surveys. Classification of occupations 1980. London: HMSO, 1980.

20 Cochrane R, Robertson A. The life events inventory: a measure of the relative severity of psycho-social stressors. $\mathcal{F}$ measure of the relative severity
Psychosom Res 1973;17:135-9.

21 Pearlin II, Schooler C. The structure of coping. 7 Health Soc Behav 1981;22:337-56.

22 Pearlin LI. Role strains and personal stress. In: Kaplan HB, ed. Psycho-social stress: trends in theory and research. New York: Academic Press, 1983:3-32.

23 Kandel DB, Davies M, Raveis VH. The stressfulness of daily social roles for women: marital, occupational and household roles. F Health Soc Behav 1985;26:64-78.

24 Robin AA. The psychological changes of normal parturition. Psychiat Ouart 1962;36:129.

25 Hooke JF, Marks PA. MMPI characteristics of pregnancy. $\mathcal{f}$ Clin Psychol 1962;18:316.

26 Elliott SA, Rugg AJ, Watson JP, Brough DI. Mood changes in pregnancy and the puerperium. Br $\mathrm{f}$ Clin Psychol 1983;22:295-308.

27 Nilsson O, Almgren P. Para natal emotional adjustment. Acta Psychiatr Scand 1970;220(Suppl):000-00.

28 Zajicek E. Psychiatric problems during pregnancy. In: Wolkind S, Zajicek E, eds. Pregnancy a psychological and social study. Zandon: Academic Press, 1981 .

29 Lips HM. A longitudinal study of the reporting of emotional and somatic symptoms during and after pregnancy. Soc Sci Med 1985;21:631-40.

30 Ballinger CB. Emotional disturbances during pregnancy and following delivery. $\mathcal{F}$ Psychosom Res 1982;26(6):629-34.

31 Brown GW, Harris T. Social origins of depression. London: Tavistock, 1978.

32 Kandel DB, Davies M. Adult sequelae of adolescent depressive symptoms. Arch Gen Psychiatr 1986;43:255-62.

33 Glassman AH, Stetner F, Walsh T, et al. Heavy smokers, smoking cessation and clonodine: results of a double blind randomized trial. 7AMA 1988;259:2862-6.

34 Polmerleau OF, Adkins D, Pertschuk M. Prediction of recidivism in smoking cessation treatment. Addict Behav 1978;3:65-70.

35 Graham $\mathrm{H}$. Smoking in pregnancy: the attitudes of expectant mothers. Soc Sci Med 1987;25(1):47-56. 